
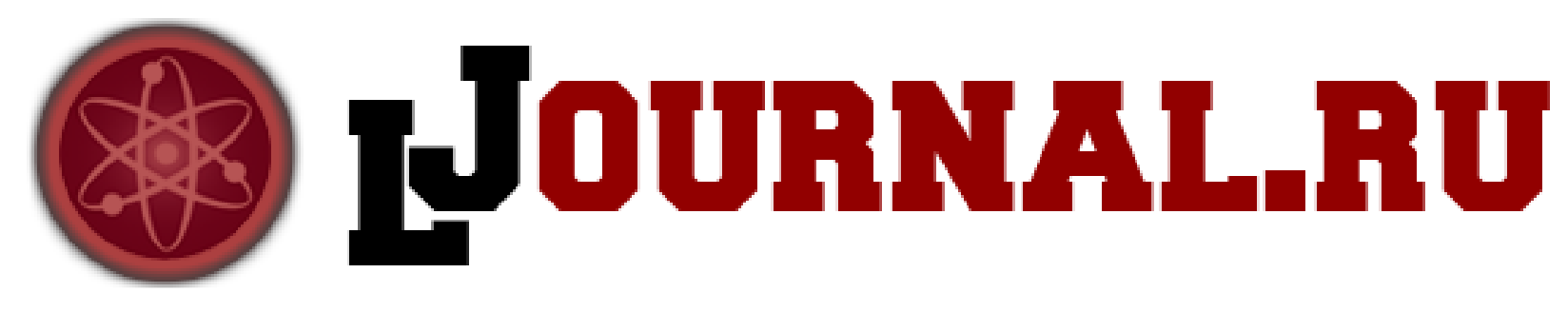

Морозов П.В., Обухов К.А.

Новосибирский государственный технический университет Новосибирск, Россия

doi: 10.18411/1j2016-2-13

\title{
Анализ методов повышения качества электрической энергии в тяговых сетях переменного тока
}

Электрические аппараты и оборудование, присоединенные к системе электроснабжения, связаны между собой кондуктивно и оказывают влияние как друг на друга, так и на саму систему электроснабжения [1]. Нормы качества энергии, устанавливаемые стандартом [2], являются критериями электромагнитной совместимости для кондуктивных электромагнитных помех в системах электроснабжения. Как известно, кондуктивная электромагнитная помеха распространяется по элементам электрической сети.

Основной задачей любой системы электроснабжения является обеспечение качества функционирования некоторой технической системы. В данном докладе в качестве такой технической системы выбрана железная дорога, электрифицированная на переменном токе. Для этого необходимо, чтобы система электроснабжения располагала соответствующей мощностью. Кроме того, система электроснабжения железной дороги должна иметь достаточный уровень электромагнитной совместимости с системой электроснабжения в целом при разнообразных условиях работы железнодорожного транспорта. Эти задачи могут быть решены только при 
правильно выбранных параметрах трансформаторных преобразователей системы электроснабжения, обеспечивающих работу оборудования в допустимых пределах и необходимое качество электрической энергии в точке присоединения.

Электрифицированные железные дороги оказывают различные мешающие влияния на смежные сооружения, в том числе на трехфазную сеть. Так, на дорогах переменного тока в питающей трехфазной системе нарушается симметрия токов и напряжений, что ведет к дополнительным потерям электрической энергии, к понижению мощности генераторов и двигателей или уменьшению срока их службы. Несимметрия напряжения возникает при неравенстве напряжений в фазах по амплитуде или отличии угла между фазами более 120 градусов. Степень несимметрии определяют с помощью метода симметричных составляющих по отношению составляющей обратной последовательности к составляющей прямой последовательности. Напряжение обратной последовательности в основном возникает из-за протекающих по сети токов обратной последовательности несимметричных нагрузок, в связи с чем в первом приближении необходимо исследовать и оценивать степень несимметрии по току. Нормально допустимое значение коэффициента несимметрии в точке присоединения тяговой сети в трехфазной сети в течение не менее 95\% каждых суток составляет 2\% [2], а предельно допустимое - 4\%. В соответствии с Правилами устройства системы тягового электроснабжения железных дорог РФ для снижения несимметрии тяговые подстанции переменного тока, в составе которых есть трехфазные и однофазные трансформаторы, необходимо подключать к линиям электропередачи с циклическим присоединением наиболее загруженных фаз тяговых подстанций к разным фазам трехфазной сети. Снижать несимметрию также можно путем пофазного размещения устройств параллельной компенсации реактивной мощности. Были выявлены и проанализированы недостатки таких способов 
симметрирования, и в качестве рекомендаций предложены усовершенствованные схемные решения для трансформаторов, которые дают несимметрию, не превышающую $2 \%$.

Система электроснабжения электрифицированной железной дороги взаимодействует с трехфазной сетью посредством тяговой подстанции, которая является точкой присоединения. Устройство тяговой подстанции зависит от системы электрической тяги, применяемой на железной дороге, т.е. определяется родом тока и напряжения, применяемого в контактной сети, а также напряжением и системой тока источника энергии со стороны трехфазной сети. Наиболее предпочтительной является структура трансформаторного преобразователя, которая обеспечивает 90-градусный сдвиг между фазными токами и напряжениями на вторичной стороне, и 120 градусов - на первичной стороне. К таким преобразователями относятся схема Вудбриджа, схема Скотта [3]. Схема Скотта обладает более простой структурой, чем схема Скотта, и, в то же время обеспечивает полную симметрию токов в первичной трехфазной сети при равных фазных нагрузках на вторичной стороне.

Дополнение вторичной стороны трансформатора Скотта шунтирующими активными фильтрами с общим емкостным накопителем энергии обеспечивает полную симметрию токов и напряжений при резко изменяющихся нагрузках. Каждый активный фильтр представляет собой коммутируемую мостовую схему, работающую в режиме или выпрямителя или инвертора. Допустимый коэффициент несинусоидальности не более $2 \%$ достигается за счет поиска оптимального соотношения количества мостовых схем и частоты переключения коммутационных элементов. Как показало моделирование трансформатора с активными фильтрами в Simulink, несинусоидальность удовлетворяет данным условиям при частоте переключения 5 кГц и 4 мостовых схемах на каждую фазу. 


\section{Литература:}

1. РД 50 713-92. Совместимость технических средств электромагнитная. Электромагнитная обстановка. Виды низкочастотных кондуктивных помех и сигналов, передаваемых по силовым линиям, в системах электроснабжения общего назначения. //М.: Изд-во стандартов,1993.-16 с.

2. Никифоров В.В. Новый стандарт по качеству электрической энергии. Основные положения и отличия от ГОСТ 13109-97// Новости электротехники, 2011.-№3.-С.15-17

3. Манусов В. 3. Исследование методов снижения несимметрии нагрузки трехфазной сети на тяговых подстанциях скоростных железных дорог переменного тока / В. З. Манусов, П. В. Морозов // Известия Транссиба. 2012. - № 2 (10). - C. 87-93.. 